\title{
Accuracy of Protein Size Estimates Based on Light Scattering Measurements
}

\author{
Ken Takeuchi, Yoichi Nakatani, Osamu Hisatomi* \\ Department of Earth and Space Science, Graduate School of Science, Osaka University, Toyonaka, Japan \\ Email: "hisatomi@ess.sci.osaka-u.ac.jp
}

Received 31 March 2014; revised 16 April 2014; accepted 23 April 2014

Copyright (C) 2014 by authors and Scientific Research Publishing Inc.

This work is licensed under the Creative Commons Attribution International License (CC BY). http://creativecommons.org/licenses/by/4.0/

(c) (i) Open Access

\section{Abstract}

There are two types of light scattering measurements: static light scattering (SLS) and dynamic light scattering (DLS). The SLS method is used to estimate the molecular weight (MW) of particles by measuring the time-averaged intensity of light scattered by the particles, whereas the DLS method is used to estimate the diffusion coefficient of particles by observing the time-correlation of scattered light intensity. These techniques have recently been applied to the investigation of the aggregation, denaturation and folding, and complex formation of proteins in solution. However, the accuracy of protein size measurement by light scattering is poorly understood. In the present study, we carried out the size measurements of five globular proteins by SLS and DLS at a detection angle of $90^{\circ}$ and compared these data to measurements made by size exclusion chromatography (SEC). The difference (\%) between the MW estimated from each method and the MW calculated from the amino acid sequence (namely the calibration residual error) was regarded as an index of measurement accuracy. The averaged calibration residual errors were 5.2 and 4.7 for SEC and SLS measurements, respectively. For the DLS measurements, the extrapolation of the apparent hydrodynamic radii to a protein concentration of zero may effectively eliminate the interparticle and hydrodynamic interactions and significantly reduced the averaged calibration residual error to $4.8 \%$. Our results suggested that the size of globular proteins can be estimated using light scattering measurements with an accuracy equivalent to that of SEC.

\section{Keywords}

Size Measurement; Light Scattering; Size Exclusion Chromatography

\section{Introduction}

To clarify the physical properties of biomolecules, it is necessary to measure their native sizes. Biochemical

*Corresponding author. 
methods such as sodium dodecyl sulfate-polyacrylamide gel electrophoresis and size exclusion chromatography (SEC) are generally used for the characterization of proteins. However, these methods are necessarily performed under restrictive conditions of temperature, salt concentration and $\mathrm{pH}$, which are not always representative of the proteins' native environments. Biophysical techniques such as sedimentation equilibrium analytical ultracentrifugation and small angle X-ray scattering (SAXS) are therefore used to determine the molecular weight (MW) of proteins in their native state. However, these methods are complex with limited availability to most researchers. Sedimentation equilibrium analytical ultracentrifugation generally requires sophisticated and expensive equipment and takes several hours to measure the size of each protein [1]. The SAXS method requires operation in a controlled area as an intense X-ray beam is used, which may result in radiation damage of the samples.

Recently, a nondestructive technique has gained popularity for exploring the size of macromolecules in solution [2]. Light scattering estimates the size and shape of particles by measuring the intensity of scattered light. There are two types of light scattering measurements: static light scattering (SLS) and dynamic light scattering (DLS). The SLS method estimates the MW of molecules by measuring the time-averaged intensity of light scattered by the particles, whereas the DLS method estimates the diffusion coefficient of particles by observing the time-correlation of scattered light intensity. The major advantages of light scattering over other techniques include the short time required to obtain data and its relative simplicity and accessibility to most researchers [2]. Light scattering has therefore frequently been used to investigate the aggregation [3] [4], denaturation and folding [5] [6], and complex formation [7]-[9] of proteins in solution. However, the accuracy of protein size measurement using light scattering methods such as DLS has been poorly evaluated thus far.

For the DLS measurements, the apparent hydrodynamic radii $\left(R_{H-a p p}\right)$ of the proteins in solution were calculated as follows:

$$
R_{H-a p p}=k_{B} T / 6 \pi \eta D
$$

where $k_{B}$ is the Boltzmann constant, $T$ is absolute temperature, $\eta$ is the viscosity coefficient and $D$ is the diffusion coefficient of the protein. Since the intensity of scattered light is very low for small proteins, high protein concentrations are required to obtain the $R_{H-a p p}$ with a sufficiently high signal-to-noise ratio. The diffusion coefficient may also be influenced by the interparticle interaction and by the hydrodynamic interaction that arises because a moving molecule induces solvent flow and hence exerts viscous forces on diffusing protein molecules nearby [5] [10]. Therefore, for DLS measurements, the protein concentration of the sample needs to be considered in order to obtain precise protein sizes.

In the present study, we measured the sizes of globular proteins by SLS and DLS at a detection angle of $90^{\circ}$ and compared the results to those obtained by SEC. The $R_{H-a p p}$ of five proteins estimated from DLS measurements increased linearly relative to their concentration, and the extrapolation of $R_{H-a p p}$ to a protein concentration of zero significantly increased the measurement accuracy. Our results suggest that the size of globular proteins in their physiological states can be estimated by light scattering methods with an accuracy equivalent to that obtained by SEC analysis.

\section{Materials and Methods}

\subsection{Materials}

We used five globular proteins: aprotinin (bovine lung; $6.5 \mathrm{kDa}$ ), ribonuclease A (bovine pancreas; $13.7 \mathrm{kDa}$ ), carbonic anhydrase (bovine erythrocytes; $29.0 \mathrm{kDa}$ ), ovalbumin (hen egg white; $43.0 \mathrm{kDa}$ ) and conalbumin (chicken egg white; $75.0 \mathrm{kDa}$ ) present in the Gel Filtration LMW Calibration Kit (GE Healthcare, Buckinghamshire, UK). All proteins were diluted with PBS buffer containing $300 \mathrm{mM} \mathrm{NaCl}$ and $50 \mathrm{mM}$ phosphate (pH 7.2). The molecular extinction coefficient at $280 \mathrm{~nm}\left(\varepsilon_{280}, \mathrm{M}^{-1} \mathrm{~cm}^{-1}\right)$ of each protein was calculated with the following formula [11]:

$$
\varepsilon_{280}=5500 \times N_{\text {Trp }}+1490 \times N_{\text {Tyr }}+125 \times N_{s-s}
$$

where $N_{T r p}, N_{T y r}$ and $N_{s-s}$ are the number of tryptophans, tyrosines and disulfide bonds, respectively, in each protein. Protein concentrations were determined from their absorbance at $280 \mathrm{~nm}$ with a UV-160 spectrophotometer (Shimadzu, Kyoto, JP), using an $\varepsilon_{280}$ of 6335 for aprotinin, 9440 for ribonuclease A, 50,420 for carbonic anhydrase, 31,775 for ovalbumin and 88,165 for conalbumin. 


\subsection{SEC Measurements}

SEC was performed using an AKTA Purifier column chromatography system with a Superdex G-75 30/10 column (GE Healthcare) in PBS buffer at room temperature $\left(25^{\circ} \mathrm{C} \pm 1^{\circ} \mathrm{C}\right)$. The concentrations and volumes of the applied samples were $22 \pm 6 \mu \mathrm{M}$ and $140 \pm 13 \mu \mathrm{L}$, respectively. The flow rate was $0.5 \mathrm{~mL} / \mathrm{min}$. The partition coefficient $\left(K_{a v}\right)$ of each protein was calculated as $K_{a v}=\left(V_{E}-V_{0}\right) /\left(V_{c}-V_{0}\right)$, where $V_{E}$ is the peak elution volume of each protein, $V_{c}$ is the column volume $(24 \mathrm{~mL})$, and $V_{0}$ is the void volume $(7.65 \mathrm{~mL})$. The calibration line was obtained by the least squares method, and the differences between the $M W_{a a}$ calculated from the amino acid sequences and the $M W_{S E C}$ calibrated from $K_{a v}$ were used as indices of measurement accuracy.

\subsection{SLS Measurements}

SLS measurements of the globular protein solutions were carried out with a Zetasizer $\mu \mathrm{V}$ system (Malvern Instruments, Worcestershire, UK) and the data were analyzed according to the method described in the handling manual. The stock solutions of each protein were diluted with PBS buffer to $1.78-2.59 \mathrm{mg} / \mathrm{mL}(275-400 \mu \mathrm{M})$ for aprotinin, $1.35-2.73 \mathrm{mg} / \mathrm{mL}(100-300 \mu \mathrm{M})$ for ribonuclease A, $0.57-1.45 \mathrm{mg} / \mathrm{mL}(20-50 \mu \mathrm{M})$ for carbonic anhydrase, $0.43-1.1 \mathrm{mg} / \mathrm{mL}(10-25 \mu \mathrm{M})$ for ovalbumin and $0.37-0.94 \mathrm{mg} / \mathrm{mL}(5-12.5 \mu \mathrm{M})$ for conalbumin. $70 \mu \mathrm{L}$ of the protein solutions were incubated at $20^{\circ} \mathrm{C}$ for $30 \mathrm{~min}$, centrifuged at $36,000 \times g$ for 10 min at $20^{\circ} \mathrm{C}$ to remove aggregates, and $50 \mu \mathrm{L}$ of each resulting supernatant were transferred to a quartz sub-micro fluorimeter cuvette (Starna Scientific, London, UK). The cuvette was placed in the cell holder of the Zetasizer $\mu \mathrm{V}$ and SLS measurements were performed without any equilibration time. Light scattering was detected at 830 $\mathrm{nm}$ with a fixed detection angle of $90^{\circ}$ and data were collected in automatic mode at $20^{\circ} \mathrm{C}$. The Rayleigh ratio $\left(R_{\theta}\right)$ was measured several times and the $M W_{\text {deb }}$ was determined using the Zetasizer Software (Version 6.20; Malvern Instruments). The following mathematical relationship was observed between $R_{\theta}$ and $M W_{d e b}$ in the SLS data:

$$
K c / R_{\theta}=1 / M W_{\text {deb }}+2 A_{2} c
$$

where $K=4 \pi^{2} n_{0}{ }^{2}(d n / d c)^{2} / N_{A} \lambda_{0}^{4}, n_{0}$ is the refractive index of the solvent, $d n / d c$ is the refractive index increment, $c$ is the solute concentration, $N_{A}$ is Avogadro's number, $\lambda_{0}$ is the wavelength of the laser, $M W_{d e b}$ is the molecular weight of particles obtained from Equation (3) and $A_{2}$ is the second virial coefficient. $K c / R_{\theta}$ was plotted against the concentration, using a solvent refractive index of 1.334 and a refractive increment of $0.186 \mathrm{~mL} / \mathrm{g}$ at $20^{\circ} \mathrm{C}[12]$.

\subsection{DLS Measurements}

DLS of the globular protein solutions was measured with a Zetasizer $\mu \mathrm{V}$ system and the data were analyzed according to the method described in the handling manual. Proteins were diluted with PBS buffer (viscosity, $\eta=$ $0.9236 \times 10^{-3} \mathrm{~Pa} \cdot \mathrm{s}$ ) to a concentration of $300-450 \mu \mathrm{M}$ for aprotinin, $100-250 \mu \mathrm{M}$ for ribonuclease $\mathrm{A}, 6-41$ $\mu \mathrm{M}$ for carbonic anhydrase, $30-60 \mu \mathrm{M}$ for ovalbumin and $2.1-6.2 \mu \mathrm{M}$ for conalbumin. $70 \mu \mathrm{L}$ aliquots of the protein solutions were incubated at $25^{\circ} \mathrm{C}$ for $30 \mathrm{~min}$ and then centrifuged at $36,000 \times \mathrm{g}$ for $10 \mathrm{~min}$ at $25^{\circ} \mathrm{C}$ to remove aggregates. $45 \mu \mathrm{L}$ of each resulting supernatant were transferred to a quartz sub-micro fluorimeter cuvette, placed in the cell holder and subjected to DLS measurements without any equilibration time. Light scattering was detected at $830 \mathrm{~nm}$ with a fixed detection angle of $90^{\circ}$ and data were collected in automatic mode at $25^{\circ} \mathrm{C}$ using a solvent refractive index of 1.334 . The z-average molecular sizes in terms of the $R_{H \text {-app }}$ in solution were determined using the Zetasizer Software (Version 6.20). DLS of each globular protein was measured several times. Standard deviations (SDs) of all $R_{H-a p p}$ values obtained from the measurements were less than 0.05 $\mathrm{nm}$. In these analyses, DLS data yielding a polydispersity index of greater than 0.3 were omitted.

\section{Results and Discussion}

\subsection{SEC}

Figure 1(a) shows the elution profiles of blue dextran (a marker to confirm $V_{0}$ ), conalbumin, ovalbumin, carbonic anhydrase, ribonuclease A and aprotinin. The $K_{a v}$ at peak volumes of the five proteins show a linear relationship with the $\log \left(M W_{a a}\right)$ (Figure 1(b)). From the regression line, the calibrated $M W_{S E C}$ were expressed as follows: 


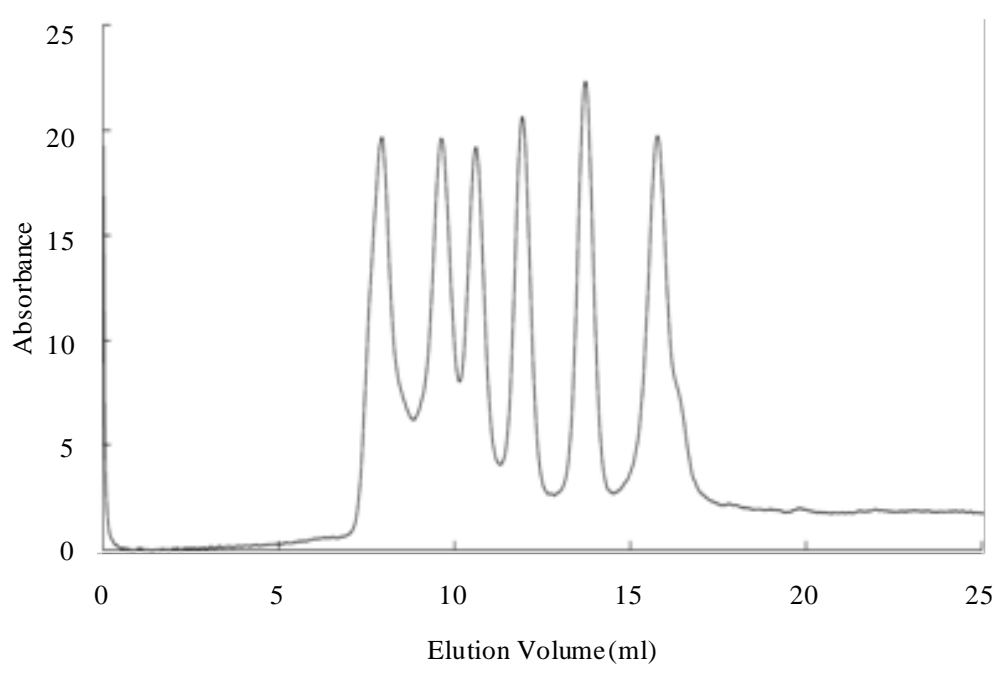

(a)

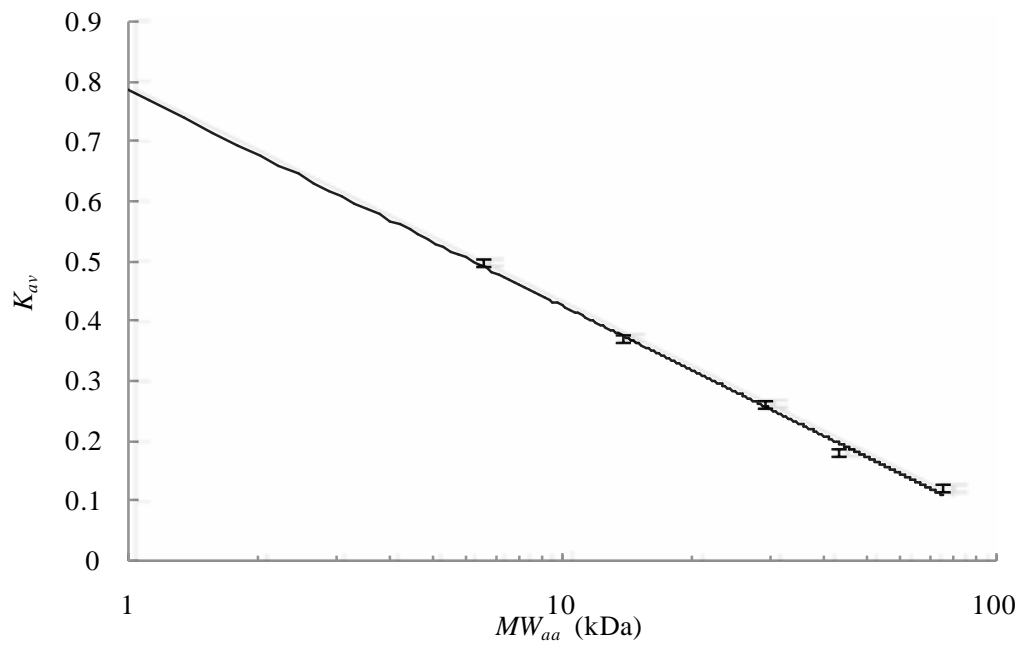

(b)

Figure 1. (a) Elution profiles of SEC monitored by the absorption at $280 \mathrm{~nm}$. The six peaks in the profiles correspond with blue dextran $(200 \mathrm{kDa})$, conalbumin (75 kDa), ovalbumin (43 kDa), carbonic anhydrase (29 kDa), ribonuclease A (13.7 kDa) and aprotinin (6.5 kDa), respectively; (b) Relationship between $M W_{a a}$ and $K_{a v}$. Bars represent the $K_{a v}$ of each protein with standard deviation $(\mathrm{SD} ; \mathrm{n}=3)$; the regression line was obtained by the least squares method.

$$
M W_{S E C}=(151 \pm 12) \times \exp \left((-6.4 \pm 0.3) \times K_{a v}\right)
$$

The difference between $M W_{a a}$ and $M W_{S E C}$, i.e. the calibration residual error for each protein, which can be regarded as an index of the accuracy of SEC measurement, is shown in Table 1. The calibration residual error for each protein was $1.5 \%-9.8 \%$ with an averaged error of $5.2 \%$ for $M W_{S E C}$.

\subsection{SLS}

The $K c / R_{\theta}$ values of carbonic anhydrase (red), ribonuclease A (gray) and aprotinin (black) are shown in Figure 2(a), while those of conalbumin (blue) and ovalbumin (green) are shown in Figure 2(b). The $K c / R_{\theta}$ values show a linear dependence on concentration, as expected from Debye's relationship (Equation (3)). The $M W_{\text {deb }}$ of each protein was obtained by extrapolation to a protein concentration of $0 \mathrm{~g} / \mathrm{mL}$. Figure 2(c) shows the relationship between the $M W_{d e b}$ and the $M W_{a a}$. From the regression line, the calibrated $M W_{S L S}$ were expressed as 
follows:

$$
M W_{\text {SLS }}=(0.95 \pm 0.03) \times M W_{\text {deb }}+(1.3 \pm 1.2)
$$

The calibration residual error of $M W_{S L S}$ for each protein is $0.1 \%-7.6 \%$ as summarized in Table 1 . The averaged error was $4.7 \%$, suggesting that the SLS method for estimating the $M W$ of globular proteins can yield measurement accuracy comparable to that of SEC.

\subsection{DLS}

Figure 3(a) shows the relationship between $R_{H-a p p}$ and the concentrations of carbonic anhydrase (red), ribonuclease A (gray) and aprotinin (black), while Figure 3(b) shows that of conalbumin (blue) and ovalbumin (green). The $R_{H-a p p}$ were observed to depend linearly on the protein concentration, as $R_{H-a p p} \simeq R_{H}(1+\theta c)$ [13], where $c$

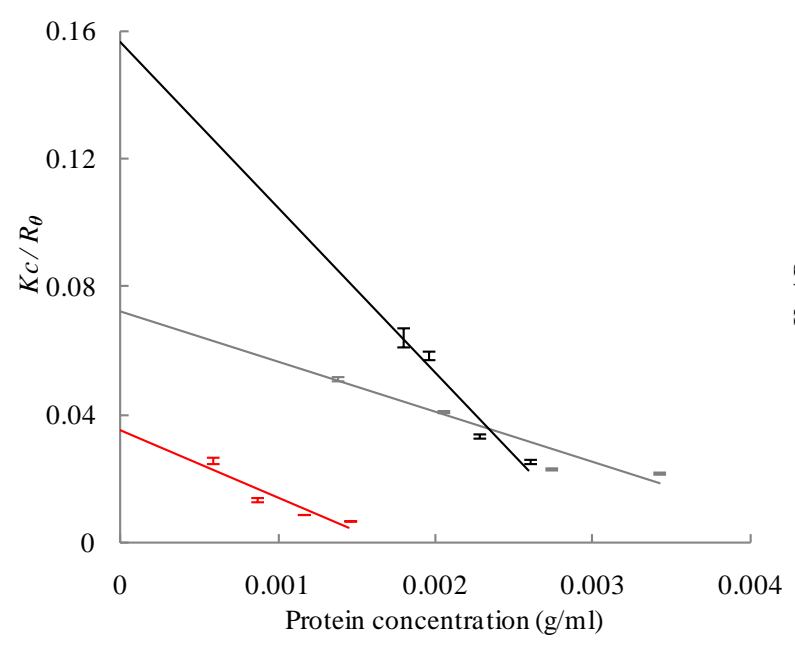

(a)

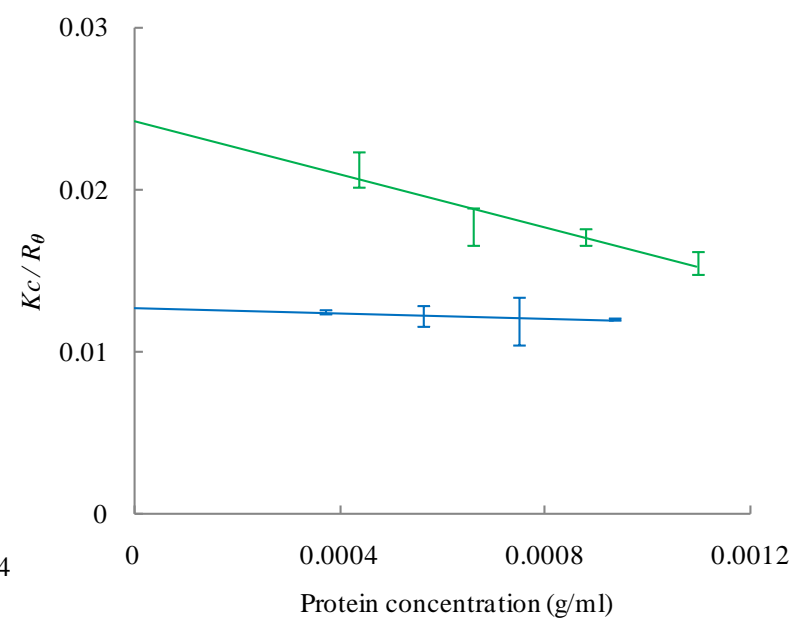

(b)

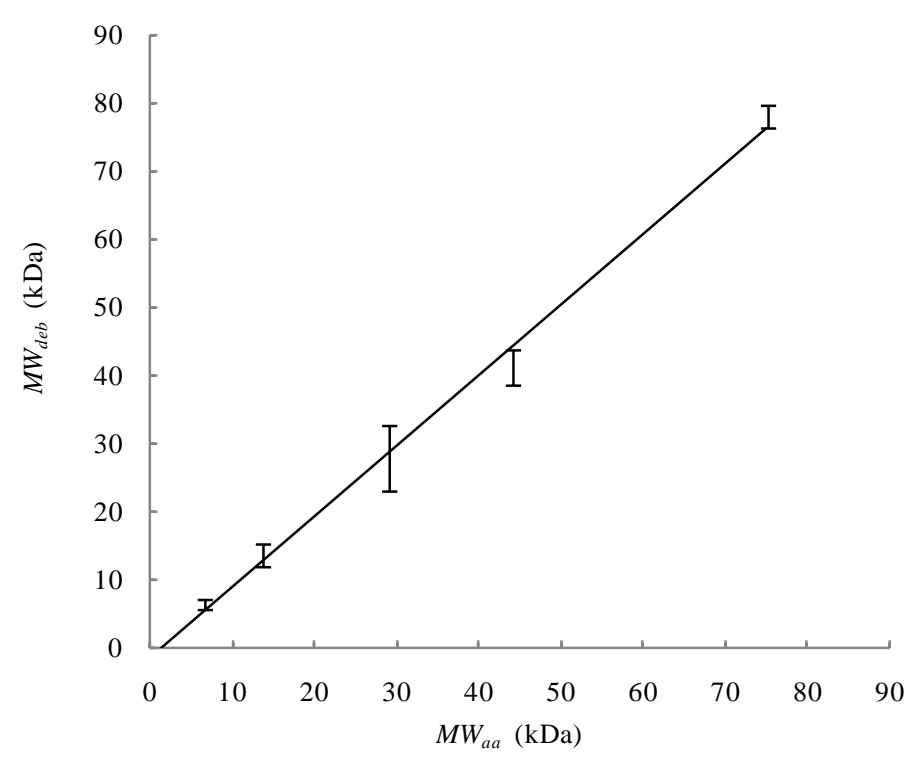

(c)

Figure 2. Dependence of $K c / R_{\theta}$ on the concentration of globular protein as observed with SLS is shown in (a) and (b). (a) The data and regression lines of carbonic anhydrase (red), ribonuclease A (gray) and aprotinin (black); (b) The data and regression lines of conalbumin (blue) and ovalbumin (green); (c) The linear relationship between $M W_{d e b}$ and $M W_{a a}$ is shown by the regression line. SDs were obtained from more than seven independent measurements. 
Table 1. Calibration residual errors (\%) and calibrated MWs (kDa) for each protein.

\begin{tabular}{ccccc}
\hline & $M W_{\text {SEC }}$ & $M W_{\text {SLS }}$ & $M W_{\text {DLS }}$ & $M W_{\text {DLS-app }}{ }^{*}$ \\
\hline Aprotinin & $3.9 \%$ & $5.6 \%$ & $3.0 \%$ & $18.6 \%$ \\
(6.5 kDa) & $(6.2)$ & $(6.1)$ & $(6.3)$ & $4.7 \%$ \\
Ribonuclease A & $1.5 \%$ & $3.0 \%$ & $(14.4)$ & $8.3 \%$ \\
(13.7 kDa) & $(13.9)$ & $(13.3)$ & $4.3 \%$ & $(12.6)$ \\
Carbonic anhydrase & $3.2 \%$ & $6.9 \%$ & $(27.7)$ & $23.2 \%$ \\
(29.0 kDa) & $(28.1)$ & $(27.0)$ & $10.0 \%$ & $(22.3)$ \\
Ovalbumin & $9.8 \%$ & $7.6 \%$ & $(47.3)$ & $45.0 \%$ \\
(43.0 kDa) & $(47.2)$ & $(39.7)$ & $2.1 \%$ & $(62.4)$ \\
Conalbumin & $7.8 \%$ & $0.1 \%$ & $(73.4)$ & $1.5 \%$ \\
(75.0 kDa) & $(69.2)$ & $(75.1)$ & $\mathbf{4 . 8 \%}$ & $\mathbf{1 9 . 3}$ \\
Average & $\mathbf{5 . 2 \%}$ & $\mathbf{4 . 7 \%}$ & & $\mathbf{1 9}$ \\
\hline
\end{tabular}

"Calibrated from the $R_{H-a p p}$ at the lowest protein concentration.

is the concentration of the protein and $\theta$ is a parameter that account for the first order effect of both interparticle and hydrodynamic interactions (corresponding to the interaction parameter of the diffusion coefficient) [5] [10]. This concentration dependency strongly suggests that these interactions reduce the diffusion constants of all five proteins; the $R_{H}$ were therefore smaller than the $R_{H-a p p}$ at practical concentrations. By extrapolation to protein concentrations of zero, we estimated the correct $R_{H}$ to be $1.29 \pm 0.06 \mathrm{~nm}$ for aprotinin, $1.73 \pm 0.03 \mathrm{~nm}$ for ribonuclease A, $2.19 \pm 0.05 \mathrm{~nm}$ for carbonic anhydrase, $2.65 \pm 0.04 \mathrm{~nm}$ for ovalbumin, and $3.10 \pm 0.01 \mathrm{~nm}$ for conalbumin.

The blue bars and regression line in Figure 3(c) show the relationship between $M W_{a a}$ and the extrapolated $R_{H}$, whereas the red bars and regression line show the relationship between the $M W_{a a}$ and $R_{H-a p p}$ at the lowest protein concentrations. The $M W_{D L S}$ and $M W_{D L S \text {-app }}$ of the globular proteins were estimated from the regression lines as follows:

$$
\begin{gathered}
M W_{D L S}=(3.1 \pm 0.3) \times R_{H}^{(2.8 \pm 0.1)} \\
M W_{D L S-a p p}=(2.3 \pm 1.0) \times R_{H-a p p}^{(2.8 \pm 0.4)}
\end{gathered}
$$

The deviations of the data points from the regression line appear to be much smaller for $R_{H}$ than for $R_{H-a p p}$. The $M W_{D L S}, M W_{D L S-a p p}$ and their calibration residual errors for $R_{H}$ and $R_{H-a p p}$ at the lowest concentration are summarized in Table 1. The calibration errors for each protein are $2.1 \%-10.0 \%$ for $M W_{D L S}$ and $1.5 \%-45.0 \%$ for $M W_{D L S \text {-app }}$, and averaged error was $4.8 \%$ for $M W_{D L S}$, which is much smaller than the $19.3 \%$ for $M W_{D L S-a p p}$. This result clearly indicated that the extrapolation of $R_{H-a p p}$ to a protein concentration of zero significantly increases the accuracy of size measurement. In the relationship of $R_{H-a p p} \simeq R_{H}(1+\theta c), \theta$ is a protein-specific parameter and the lowest protein concentrations to obtain the $R_{H-a p p}$ with a sufficiently high signal-to-noise ratio are different for each protein. The extrapolation of $R_{H-a p p}$ to a protein concentration of zero may effectively eliminate the interparticle and hydrodynamic interactions of each protein, and possibly contribute to increase the measurement accuracy.

Equation (6-1) can be expressed as follows:

$$
M W_{D L S}=(0.74 \pm 0.07) \times(4 \pi / 3) \cdot R_{H}^{(2.8 \pm 0.1)}
$$

Since the power index of $R_{H}$ is close to 3, the latter term can be regarded as the volume of protein. Also, the value of $0.74 \pm 0.07$ is close to the reported densities of globular proteins $\left(0.79-0.87 \mathrm{kDa} / \mathrm{nm}^{3}\right)$ [14] [15]. The observed deviations from the theoretical values are probably correlated with the solvation of proteins in PBS buffer.

\subsection{Accuracy of Size Measurements}

Figure 4 shows the $M W_{S E C}$ (blue bars and regression line), $M W_{S L S}$ (green bars and regression line) and $M W_{D L S}$ (red bars and regression line) plotted against the $M W_{a a}$. The calibration residual errors(\%) and estimated $M W s$ $(\mathrm{kDa})$ are shown in Table 1 . The errors of three $M W_{S}\left(M W_{S E C}, M W_{S L S}\right.$ and $\left.M W_{D L S}\right)$ were less than $10 \%$ for each 
protein, and the averaged errors were 4.7\% - 5.2\%. SEC, SLS and DLS therefore show comparable accuracy in the size measurement of globular proteins.

\section{Summary and Conclusion}

Light scattering is a method that can be used to measure the size of biomolecules relatively quickly without incurring radiation damage. The present study revealed that the extrapolation of $R_{H-\text { app }}$ to a protein concentration of zero significantly increases the accuracy of size measurement for DLS, which led to the size estimation of globular proteins with an accuracy equivalent to that of SEC. We hope these results will promote further utilization of light scattering methods, not only for the size estimation, but also for analyses of conformational change, oligomeric structure and protein complex formation of various proteins.

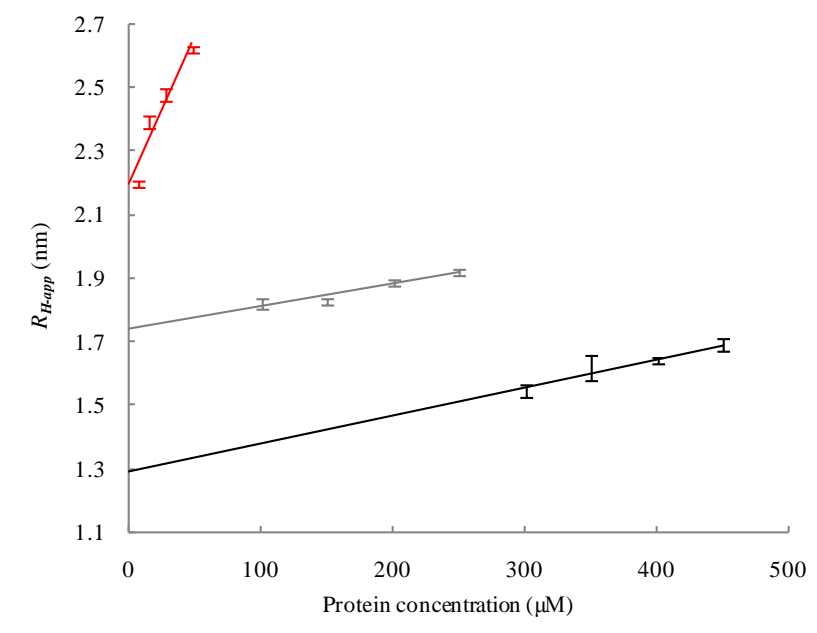

(a)

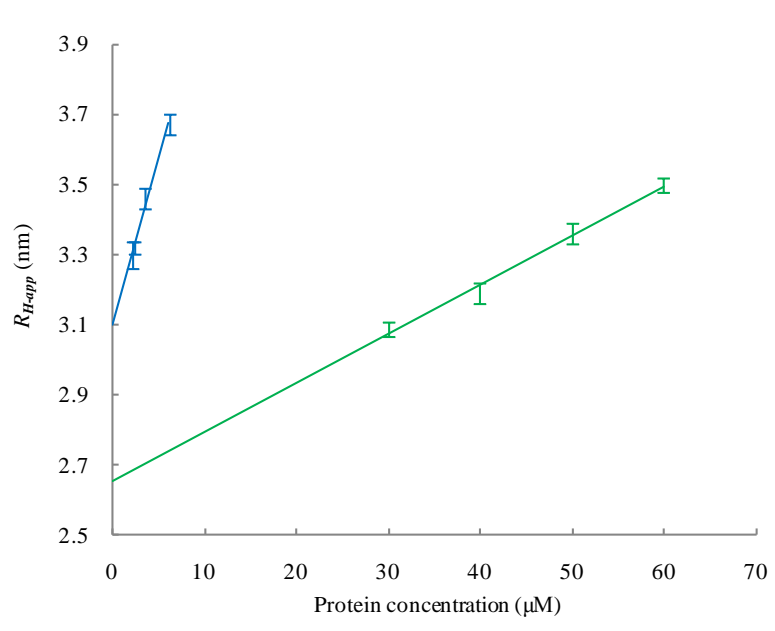

(b)

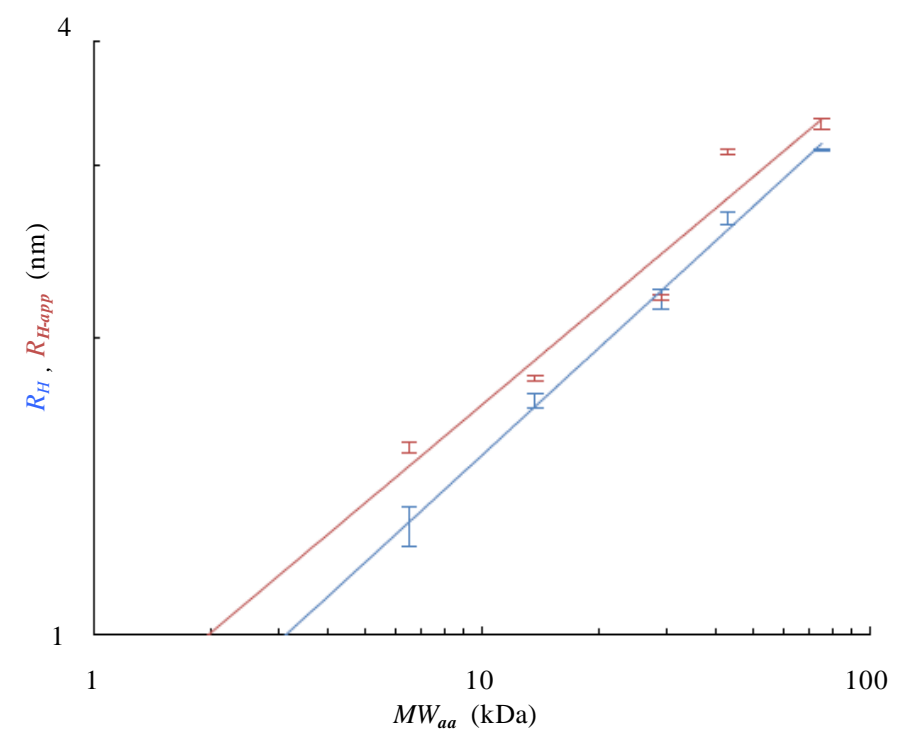

(c)

Figure 3. Dependence of $R_{H-a p p}$ on the concentration of globular protein as observed with DLS is shown in (a) and (b). (a) The bars and regression lines of carbonic anhydrase (red), ribonuclease A (gray) and aprotinin (black); (b) The bars and regression lines of conalbumin (blue) and ovalbumin (green); (c) Bars and regression lines obtained from the extrapolated $R_{H}$ (blue) and the $R_{H \text {-app }}$ at the lowest concentration (red). The formulae of the blue and red regression lines are

$R_{H}=(0.66 \pm 0.01) \times M W_{a a}^{(0.36 \pm 0.01)}$ and $R_{H-a p p}=(0.79 \pm 0.07) \times M W_{a a}^{(0.33 \pm 0.03)}$, respectively. SDs were obtained from more than nine independent measurements. 


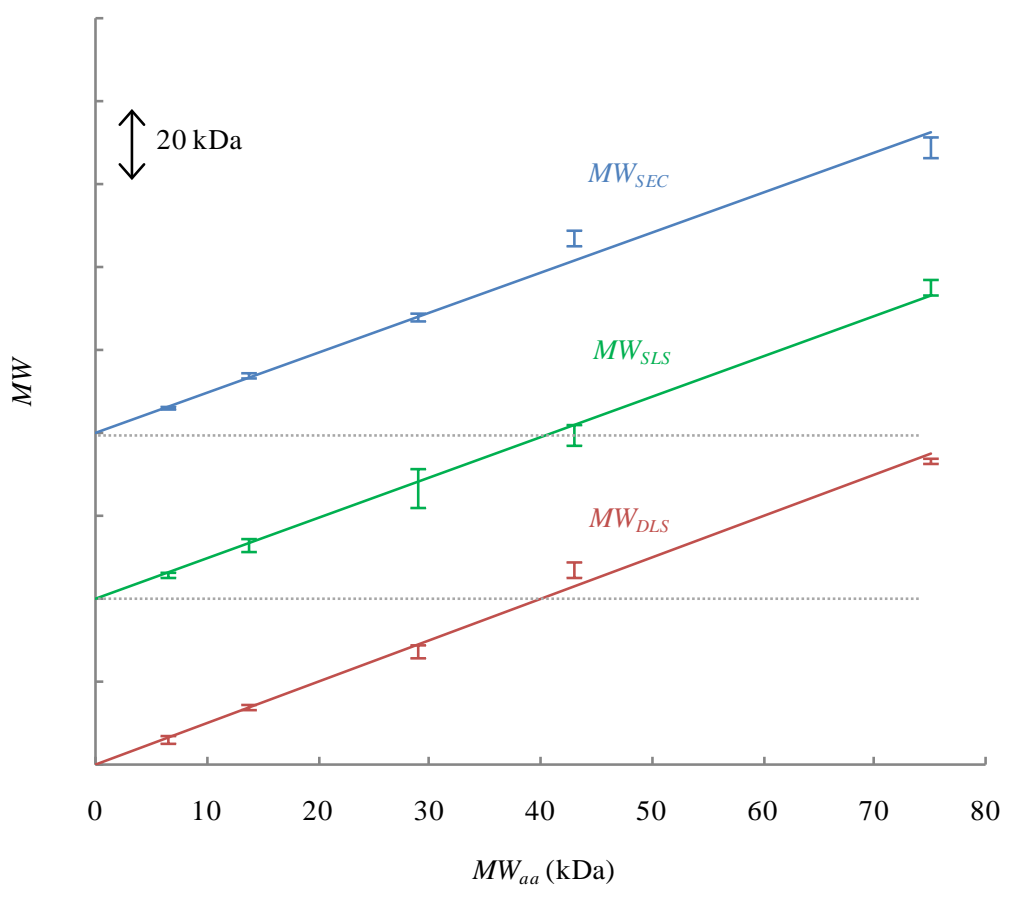

Figure 4. Relationships between $M W_{S E C}$ (blue), $M W_{S L S}$ (green) and $M W_{D L S}$ (red) versus $M W_{a a}$. The bars and regression lines for $M W_{S E C}, M W_{S L S}$ and $M W_{D L S}$ are longitudinally shifted to avoid overlapping of the data. The $y$-axis is marked at intervals of $20 \mathrm{kDa}$.

\section{Acknowledgements}

The authors thank Dr. Satoru Tokutomi at Osaka Prefecture University, and Dr. Norio Hamada and Dr. Ryosuke Nakamura at Osaka University for helpful suggestions and discussions. This research was partly supported by a Grant-in-Aid for Scientific Research on Innovative Areas (No. 23120517 to O.H.) from The Ministry of Education, Culture, Sports, Science and Technology, and by a Grant-in-Aid for Scientific Research (C) (No. 22570162 to O.H.) from the Japan Society for the Promotion of Science.

\section{References}

[1] Laue, T.M. and Rhodes, D.G. (1990) Determination of Size, Molecular Weight, and Presence of Subunits. Methods in Enzymology, 182, 566-587. http://dx.doi.org/10.1016/0076-6879(90)82045-4

[2] Murphy, R.M. (1997) Static and Dynamic Light Scattering of Biological Macromolecules: What Can We Learn? Current Opinion in Biotechnology, 8, 25-30. http://dx.doi.org/10.1016/S0958-1669(97)80153-X

[3] Bohidar, H.B. (1998) Light Scattering and Viscosity Study of Heat Aggregation of Insulin. Biopolymers, 45, 1-8. http://dx.doi.org/10.1002/(SICI)1097-0282(199801)45:1<1::AID-BIP1>3.0.CO;2-X

[4] Sasahara, K., Yagi, H., Sakai, M., Naiki, H. and Goto, Y. (2008) Amyloid Nucleation Triggered by Agitation of ß2-Microglobulin under Acidic and Neutral pH Conditions. Biochemistry, 47, 2650-2660. http://dx.doi.org/10.1021/bi701968g

[5] Liu, W., Cellmer, T., Keerl, D., Prausnitz, J.M. and Blanch, H.W. (2005) Interactions of Lysozyme in Guanidinium Chloride Solutions from Static and Dynamic Light-Scattering Measurements. Biotechnology and Bioengineering, 90, 482-490. http://dx.doi.org/10.1002/bit.20442

[6] Rabbani, G., Kaur, J., Ahmad, E., Khan, R.H. and Jain, S.K. (2014) Structural Characteristics of Thermostable Immunogenic Outer Membrane Protein from Salmonella enterica serovar Typhi. Applied Microbiology and Biotechnology, 98, 2533-2543. http://dx.doi.org/10.1007/s00253-013-5123-3

[7] Papish, A.L., Tari, L.W. and Vogel, H.J. (2002) Dynamic Light Scattering Study of Calmodulin-Target Peptide Complexes. Biophysical Journal, 83, 1455-1464. http://dx.doi.org/10.1016/S0006-3495(02)73916-7

[8] Nobbmann, U., Connah, M., Fish, B., Varley, P., Gee, C., Mulot, S., Chen, J., Zhou, L., Lu, Y., Shen, F., Yi, J. and 
Harding, S.E. (2007) Dynamic Light Scattering as a Relative Tool for Assessing the Molecular Integrity and Stability of Monoclonal Antibodies. Biotechnology and Genetic Engineering Reviews, 24, 117-128. http://dx.doi.org/10.1016/S0006-3495(02)73916-7

[9] Hanlon, A.D., Larkin, M.I. and Reddick, R.M. (2010) Free-Solution, Label-Free Protein-Protein Interactions Characterized by Dynamic Light Scattering. Biophysical Journal, 98, 297-304. http://dx.doi.org/10.1016/j.bpj.2009.09.061

[10] Rubin, J., Miguel, A.S., Bommarius, A.S. and Behrens, S.H. (2010) Correlating Aggregation Kinetics and Stationary Diffusion in Protein-Sodium Salt Systems Observed with Dynamic Light Scattering. The Journal of Physical Chemistry B, 114, 4383-4387. http://dx.doi.org/10.1021/jp912126w

[11] Grimsley, G.R. and Pace, C.N. (2004) Spectrophotometric Determination of Protein Concentration. Current Protocols in Protein Science, 33, 3.1.1-3.1.9. http://onlinelibrary.wiley.com/doi/10.1002/0471140864.ps0301s33/abstract;jsessionid=61664A5A266A57FB2E4AF38 C775A4577.f03t03

[12] Wen, J., Arakawa, T. and Philo, J.S. (1996) Size-Exclusion Chromatography with On-Line Light-Scattering, Absorbance, and Refractive Index Detectors for Studying Proteins and Their Interactions. Analytical Biochemistry, 240, 155166. http://dx.doi.org/10.1006/abio.1996.0345

[13] Hisatomi, O., Takeuchi, K., Zikihara, K., Ookubo, Y., Nakatani, Y., Takahashi, F., Tokutomi, S. and Kataoka, H. (2013) Blue Light-Induced Conformational Changes in a Light-Regulated Transcription Factor, Aureochrome-1. Plant Cell Physiology, 54, 93-106. http://dx.doi.org/10.1093/pcp/pcs160

[14] Gekko, K. and Noguchi, H. (1979) Compressibility of Globular Proteins in Water at $25^{\circ} \mathrm{C}$. The Journal of Physical Chemistry, 83, 2706-2714. http://dx.doi.org/10.1021/j100484a006

[15] Gekko, K. and Hasegawa, Y. (1986) Compressibility-Structure Relationship of Globular Proteins. Biochemistry, 25, 6563-6571. http://dx.doi.org/10.1021/bi00369a034 